\title{
Derecho a equivocarse: excusas e inocencia epistémica
}

\section{Right to be wrong: excuses and epistemic innocence}

\author{
Rodrigo Laera \\ Orcid: https://orcid.org/0000-0002-5132-7631 - E-mail: rodrigolaera@gmail.com
}

\section{RESUMEN}

Si un sujeto $S$ atribuye conocimiento ignorando evidencias disponibles, entonces $S$ no será culpable de tal atribución y, por lo tanto, no será epistémicamente irresponsable, cuando: (a) no es consciente de su propia ignorancia y (b) quienes lo juzgan, explícita o implícitamente, se ponen en el lugar de él y reconocen que no serían conscientes de su ignorancia. En este escrito se defenderá la aplicación de semejante principio, no sólo en lo que respecta a las atribuciones de conocimiento en contextos ordinarios, sino también en lo que respecta a los contextos más exigentes.

Palabras claves: Excusas epistémicas. Inocencia. Pragmatismo. Atribuciones de conocimiento.

\begin{abstract}
If a subject $S$ attributes knowledge ignoring available evidence, then $S$ will not be guilty of such attribution and, therefore, will not be epistemically irresponsible, when: (a) he is not aware of his own ignorance and (b) those who judge him, explicitly or implicitly, they put themselves in his place and acknowledge that they would not be aware of his ignorance. In this paper the application of such a principle will be defended, not only with regard to the attributions of knowledge in ordinary contexts, but also with regard to the most demanding contexts.
\end{abstract}

Keywords: Epistemic excuses. Innocence. Pragmatism. Attributions of knowledge. 


\section{Introducción}

Generalmente, las atribuciones de conocimiento del estilo "S sabe que $p$ " funcionan con una falible presunción de verdad'. Por lo tanto, en la vida diaria no hay nada irracional en que alguien afirme saber que $p$ y que luego lo niegue, especialmente después de reflexionar acerca de ello.

Imagínese el siguiente caso en el que alguien le atribuye erróneamente conocimiento a otra persona: Juan invita a su fiesta de cumpleaños a María, presuponiendo que conoce la manera de llegar su casa porque le dio la dirección exacta y porque sabe que tiene un GPS en el automóvil. Al tardar demasiado, alguien pregunta si María se ha perdido y Juan, sobre la base de la evidencia de que María tiene un GPS, responde que ella sabe cómo llegar y que la demora se debe seguramente a otro motivo. Sin embargo, María se pierde y Juan atribuyó erróneamente conocimiento.

Se puede pensar que Juan, al ser responsable de su atribución, también lo es de su yerro. Así, al atribuir conocimiento sin considerar la posibilidad de que María pudo haber olvidado la dirección para introducirla en el GPS, se concluye que Juan ha excedido el límite razonable de lo que se presupone verdadero, lo que parece ser un acto de irresponsabilidad epistémica. Sin embargo, si alguien acusara a Juan de irresponsable, él podría explicar los porqués de su falsa atribución. En este contexto, podría apelar a una batería de razones pertinentes: la evidencia de haberle dado la dirección exacta a María y que, al conocerla, sabe que ella no acostumbra a olvidarse las cosas; la seguridad de que la gente no se suele perderse cuando tienen un GPS; que ella tenía cómo comunicarse con él en el caso que estuviera perdida, y así sucesivamente. Llámese a este tipo de razones que pretenden justificar una atribución falsa de conocimiento: excusas epistémicas.

Como las excusas ordinarias - aquellas que justifican el comportamiento de quienes obran mal -, las excusas epistémicas parecen adecuadas en algunos casos, aunque no en todos. Y esto es así porque la función de las excusas es librarnos de la culpa de no haber considerado posibilidades distintas a las consideradas. No obstante, a diferencia de las excusas ordinarias, las epistémicas parecen responder a una pretensión de verdad. Es decir, no haber considerado que la elección de atribuir el conocimiento de que $p$ no haya merecido mayor reflexión. El desafío consiste en pensar un principio lo suficientemente general que haga que las excusas sean aceptables y que uno sea inocente de hacer atribuciones falsas tanto en lo que respecta a otros como a uno mismo. Justamente, en el presente escrito se sostiene que para que un sujeto sea inocente al enunciar falsas atribuciones no solamente tiene que ser capaz de brindar las excusas epistémicas pertinentes, sino que además debe satisfacer dos condiciones más: (a) que no sea consciente de su propia ignorancia y (b) que quienes lo juzgan puedan ponerse en el lugar de quien atribuye falsamente, reconociendo-implícita o explícitamente - que muy probablemente también, no siendo conscientes de su ignorancia, hubieran hecho la misma falsa atribución.

Volviendo al cumpleaños de Juan, no sería responsable de atribuir erróneamente conocimiento bajo ambas condiciones. (a) Juan no era consciente de su propia ignorancia, ya que cuando le da la dirección para llegar a su casa, elimina automáticamente la posibilidad de que ella la olvide. Esto ocurre porque nadie da algo teniendo la seguridad de que quien lo recibe lo va a perder. Al considerar que hay alguna probabilidad de que lo pierda, también es capaz de considerar las excusas por las que esa probabilidad es o no relevante para el

\footnotetext{
En este sentido, ninguna atribución de conocimiento se encuentra conclusivamente justificada por la evidencia disponible. Para un desarrollo de esta posición y que se relaciona con la idea de este trabajo, véase: Feldman (1981). Cfr., Bonjour (2010) o bien Hetherington (2013).
} 
éxito de la atribución. No obstante, la mera intención de conocer algo no hace inocente a Juan cuando atribuye conocimiento, las atribuciones, como la culpa, debe ser reconocida por los interlocutores ${ }^{2}$. Esto nos conduce a (b), si se apela a un espectador imparcial, que se ponga en el lugar de Juan, cualquier agente que estuviera en su lugar - léase también en el mismo contexto- muy probablemente hubiera atribuido conocimiento de la misma manera que lo hizo Juan. Pero ¿son suficientes estas dos condiciones? ¿De qué manera interactúan con las evidencias disponibles? La siguiente sección girará en torno a la primera pregunta, mientras que en la tercera sección se abordará la pregunta siguiente. En la cuarta sección se expondrán cinco objeciones con sus respectivas respuestas, dejando la última sección para una breve conclusión.

\section{Segundo: el derecho a equivocarnos}

Cuando alguien ignora algo, siempre puede dar razones acerca de su ignorancia. De la misma manera, cuando alguien atribuye falsamente conocimiento, puede dar razones o excusarse de su falsa atribución. Análogamente a los contextos jurídicos se puede distinguir entre excusas que exculpan totalmente - que se usan como eximentes - y otras que exculpan parcialmente - que se usan como atenuantes - y una atribución falsa de conocimiento puede ser defendida dialécticamente de ambas maneras, dependiendo del grado de aceptación de la defensa y la fuerza de los argumentos. Juan está equivocado y se puede decir que es responsable parcialmente o totalmente de su error, dependiendo de la responsabilidad que se le atribuya y el grado de convicción que generen sus excusas.

Pero quizás sea directamente injusto culparlo, pues nadie es capaz de considerar todas las alternativas posibles para atribuir conocimiento con seguridad. Si no es sensato evaluar todas las alternativas posibles por las que María está llegando tarde, entonces siempre puede haber una alternativa posible que no esté siendo considerada y que haga falsa la atribución de Juan. Si basta con considerar aquellas circunstancias que se suponen plausibles, entonces la atribución falsa de conocimiento se basará en que la mera ignorancia pueda servir de excusa que lo exculpa totalmente. Por lo tanto, cuanto más se ignora, hay menos posibilidades de ser culpable al atribuir falsamente conocimiento. Lo cual parece una consecuencia absurda. En respuesta a esto se puede pensar que para que Juan sea epistémicamente inocente y que sus excusas no sean un acto más de irresponsabilidad, tuvo que haber tenido la intención de haber valorado correctamente las evidencias disponibles y haber tratado de seguirlas. Sin embargo, tampoco parece una buena idea dejar todo en manos de la intencionalidad. Pero entonces: ¿cómo distinguir aquellas posibilidades que deben ser consideradas de las que no? Es decir ¿Cómo distinguir las buenas excusas -aquellas que eximen de culpabilidad epistémica- de las malas excusas?

La eficacia de una excusa es relativa a cada una de las creencias que se la compara. Es decir, si alguien pone como excusa que todo el mundo puede equivocarse, esta puede servir en casos en los que todos los que acusan también se equivocarían y no en casos en los que acusan no se equivocarían ${ }^{3}$. Los casos del estilo de Gettier pueden ayudar a aclarar este punto si los adaptamos un poco. Supóngase que Juan está viajando por la carretera y ve a su costado una

\footnotetext{
2 Por ejemplo Alston (2005) ha criticado fuertemente la intuición de que $S$ tiene responsabilidad sobre algunas de sus creencias a causa de algún hecho de su deliberación que todavía le parezca correcto. Sin embargo, las buenas intenciones por sí solas no son suficientes para establecer responsabilidades, es necesario que dichas intenciones sean reconocidas por otros sujetos.

${ }_{3}^{3}$ Para una línea epistémica alternativa que responde a influencias irrelevantes, véase: Vavova (2018).
} 
buena cantidad de graneros, de manera que señala algo que parece ser exactamente un granero. Debido a esto, María, que lo acompaña en el automóvil, le atribuye conocimiento a Juan: "Juan sabe que hay un granero al costado de la carretera". De modo que María cree justificadamente que Juan sabe que está viendo un granero. Sin embargo, María y Juan desconocen que en la región se han construido graneros falsos, debido a la filmación de una película, solo ven las fachadas de graneros y no graneros auténticos. A pesar de ello, fruto de la casualidad, lo que Juan había visto sí era uno de los pocos casos de auténticos graneros en la zona, por lo que María le atribuyó verazmente conocimiento a Juan 4 .

Ahora bien, María se equivoca cuando le atribuye conocimiento a Juan, pero su equivocación no es producto de una especie de desidia, cualquier persona en el mismo lugar de María también se equivocaría. Por supuesto, Juan también se equivoca al señalar un granero como si fuera verdadero, porque cree que todos los graneros lo son. El error de Juan tampoco es fruto de cierta indolencia epistémica, cualquiera que estuviera en el lugar de él hubiera creído lo mismo ${ }^{5}$. La lección que nace de este tipo de casos es que muchas veces la excusas acerca de porqué se atribuye conocimiento exceden nuestra capacidad contrastar posibilidades. En este sentido, las capacidades discriminatorias en determinados contextos son limitadas, como sucede con un granero auténtico y otro falso ${ }^{6}$.

En casos como el anterior, el acceso a la verdad se encuentra bastante restringido, pero Juan y María han intentado todo cuanto se espera que se intente para alcanzarla. Si esto es así, entonces las excusas que realmente funcionan tienen que ser aceptadas por quienes las juzgan o las evalúan. Cuando se trata de cuestiones relativas a la percepción, todo lo que se espera de una persona, en condiciones normales o cotidianas, es que afirme lo que percibe atribuyendo el correspondiente conocimiento. Esto ocurre aunque la información disponible sea incompleta o la capacidad de procesarla imperfecta.

De hecho, los sujetos tienden a sacar inferencias de la información disponible, no se conforman con una mera descripción del fenómeno. Por ejemplo, si Juan hubiera dicho "veo un objeto con forma de granero" describiría más cautamente el fenómeno y sería igual de sencillo atribuirle conocimiento. Incluso, en contextos semejantes resulta menos riesgoso, porque el enunciado "veo un granero" se encuentra integrado en el enunciado "veo un objeto con forma de granero". La excusa epistémica se basa en pensar como improbable aquellas posibilidades que solemos pasar por alto. Nuevamente, en este tipo de casos no hay un sentido en el cual "Juan debería haber sabido que el granero que ve muy probablemente sea un falso granero", pues no estamos tratando con una atribución imprudente o temeraria, Juan no obra con mala intención para que María se equivoque al atribuirle conocimiento, como tampoco se puede afirmar que su atribución es el producto de cierta desidia intelectual. María es epistémicamente inocente, pues cualquiera en su lugar hubiera atribuido conocimiento como lo hizo ella, de la misma manera que Juan. Así, se puede formular el siguiente principio de inocencia epistémica (IE):

IE: $S$ es epistémicamente inocente al atribuir conocimiento, cuando quienes se ponen en su lugar reconocen, implícita o explícitamente, que muy probablemente también hubieran atribuido conocimiento ${ }^{7}$.

4 Si bien el caso de los falsos graneros, tal como lo expone Goldman (1976) no es estrictamente como los casos expuestos por Gettier, no es necesario para nuestros propósitos presentar las diferencias.

${ }^{5}$ Esta posición no debe confundirse con la teoría de las alternativas relevantes tradicional, por ejemplo la de Lewis (1996), quien sostiene que $S$ sabe que $p$ si y solo si $p$ es verdadero en cada posibilidad relevante no eliminada.

6 Vale la pena aclarar que este punto de vista no es exactamente el del contrastavismo tradicional que sostiene que "S sabe que $p^{\text {" }}$ es la forma de una expresión que se expande a "S sabe que $p$, en vez de q". Cfr., Morton, (2003); Schaffer $(2004,2012)$.

${ }^{7}$ Nótese que este enfoque difiere del congnitivo-teleológico presentado por Sullivan-Bissett (2015) para quien una cognición es epistémicamente inocente si brinda algún beneficio epistémico al sujeto que de otro modo no sería posible porque las 
Al igual que en un juicio por jurados, el principio de inocencia está sujeto a debate. Es justamente dentro de este debate -semántico en este caso- que surgen las excusas, aquellas que son pertinentes y las que no lo son. En consecuencia, se puede formular un principio de excusas epistémicas (EE) apoyado en el anterior de inocencia:

EE: $S$ ofrece una excusa epistémica, si ofrece una explicación razonable de porqué atribuyó conocimiento.

De este modo, si la explicación razonable es reconocida - implícita o explícitamente por los interlocutores, tal que cualquiera en el lugar de quien la enuncia hubiera atribuido conocimiento, entonces la excusa funciona para conceder inocencia epistémica, pues como las atribuciones de conocimiento son falibles, todos tenemos derecho a equivocarnos.

Dos aclaraciones a tener en cuenta. En primer lugar, tener derecho a equivocarse no quiere decir atribuir conocimiento indiscriminadamente. Generalmente cuando alguien se equivoca en sus atribuciones, no es consciente de su propia ignorancia ni de su propio error. En este sentido, Juan no era consciente de su propia ignorancia y quienes se pusieran en el lugar de él, también reconocerían no ser conscientes. El hecho de que no haya atribuido conocimiento sabiendo de su equivocación hizo que Juan sea inocente epistémicamente, pudiendo esgrimir excusas razonables ${ }^{8}$. En segundo lugar, alguien es culpable de una falsa atribución cuando quienes juzgan reconocen que actuó y reflexionó de forma indolente o deshonesta. Por supuesto, nadie es culpable de no reflexionar inusualmente, más allá de las exigencias propias del contexto, especialmente en casos donde se requiere un esfuerzo intelectual o de información muy grande para un asunto cuya importancia no lo merece ${ }^{9}$. En este sentido, el esfuerzo por contrastar posibles evidencias para nuestras atribuciones depende de un esfuerzo cuyas circunstancias muchas veces no lo amerita. En el caso de los graneros, la verdad o falsedad es tan poco importante en la vida de Juan, y las posibilidades que informan de la ignorancia del agenta tan costosa, sumado a la alta probabilidad de acertar con la mera percepción, que la atribución de conocimiento puede ser pensada como inocente sea cual fuere el resultado. Esto quiere decir que, como en el caso de los graneros simulados, las atribuciones de conocimiento falsas producto del azar también están sujetas tanto a la IE como la EE.

Supóngase que María es una invitada muy importante para el cumpleaños de Juan de tal suerte que no se pueda realizar sin ella, en ese caso haberle dado meramente la dirección, aun sabiendo que tiene GPS, implicaría no haber hecho un esfuerzo suficiente. Juan, entonces, podría ser acusado de indolente respecto su capacidad de obtener la información necesaria como para atribuir conocimiento verazmente. Cuando las circunstancias o el contexto exigen un mayor esfuerzo epistémico, se hace más complicado presentar excusas ante una atribución falsa de conocimiento.

\section{Tercero: pragmática y contraste}

Tanto el IE como EE muestran una relación tríadica en la manera de entender las atribuciones de conocimiento. Generalmente, la relación de conocimiento es diádica: hay un

cogniciones alternativas (menos epistémicamente defectuosas) que podrían brindar el mismo beneficio no están disponibles para el sujeto en ese momento.

${ }^{8}$ Es oportuno comentar que la estrategia donde la responsabilidad (o culpabilidad) epistémica no sería la indolencia o la desidia, sino la deshonestidad también puede implicar excusas. Los casos de deshonestidad al atribuir conocimiento son frecuentes pero muy difíciles de evaluar, si fuera el caso Juan sería culpable de su falsa atribución, aunque se encuentre eximido de culpa debido a su manera de excusarse.

9 Para una línea de pensamiento similar a esta, véase: Stanley (2005). 
sujeto que conoce y un objeto que es conocido, con las atribuciones sucede lo mismo, un sujeto de la atribución y un objeto que es su referencia o referente. En cambio, en los casos presentados la relación es tríadica. Por un lado, el sujeto, con su capacidad para discriminar posibilidades de acuerdo con las exigencias de las circunstancias que atraviesa. Por otro lado, el objeto que es hecho referido por la atribución. Por último, las posibilidades discriminadas, las que son plausibles como las que no lo son, de acuerdo con la información disponible.

La tercera pata de la relación es la más confusa porque funciona como mediación de las dos anteriores. Cuando Juan atribuye conocimiento a María, en vez de decir solamente que María sabe el camino a la fiesta de cumpleaños, además está diciendo que hay muchas razones que hacen baja a la probabilidad de que se pierda. Esta relación no es meramente una invención filosófica, está también fijada en el sentido común, y emerge hacia la superficie en forma de excusa.

La relación tríadica también está amparada con la capacidad de ponernos en el lugar de otro, fundamentando el principio de inocencia epistémica. En este sentido, las preguntas que subyacen al principio de inocencia, pueden ser del estilo "¿realmente tenía Juan la opción de elegir y de evaluar distinto?"“" ¿Juan debería haber evaluado bien o hizo los esfuerzos suficientes para una buena evaluación, aunque su atribución de conocimiento fuera falsa?"' ¿La información que es desconocida para Juan podría ser desconocida para cualquiera que se encontrara en la misma situación?" Así, las atribuciones de conocimiento tienen un espacio de discusión implícito. Pero con esto no se quiere sostener livianamente que cada vez que se realiza una atribución sea posible extraer la información del contexto suficiente para alcanzar a completar el recurso faltante con el que contrastarla. Dicho de otra manera, el contexto no siempre es tan rico que nos brinda la posibilidad de atribuir conocimiento sin ningún tipo de perjuicio. El contexto no es ni un agujero negro semántico -incapaz de ser interpelado- ni la respuesta a todas nuestras preguntas.

Si bien Juan no podría haber obrado de distinta manera, pues las evidencias de las que disponía lo llevaban a la conclusión de que María sí sabía el camino. Por supuesto, también podría haber interpretado el contexto de distinta manera y, quizás siendo más cauteloso, no haberle atribuido conocimiento a María. Esto lleva a pensar que las atribuciones de conocimiento no comparan semánticamente una proposición con pretensiones de verdad con otra presumiblemente falsa, sino con un plexo de proposiciones posibles que pueden ser consideradas falsas. Es más, EE sugiere que atribuir el conocimiento de que $p$ es no atribuir conocimiento de todas las $q$ que implican no- $p$. Por esto, el enfoque que suscribe IE debe ser complementado con cierta invasión pragmática. De lo contrario parece complicado explicar cómo las diferentes alternativas expuestas en las excusas epistémicas convergen, generando diferentes implicaciones respecto a la información basada en evidencias disponibles ${ }^{10}$. Así, las condiciones expuestas de EE y IE por sí solas no son suficientes, deben estar relacionadas con cierta invasión pragmática, donde los factores no relacionados con la verdad de un agente resultan relevantes para el estado epistémico de sus atribuciones de conocimiento ${ }^{11}$.

Como se ha propuesto anteriormente, que alguien ponga en el lugar de quien atribuye, teniendo en cuenta su contexto, no significa que siempre haya acuerdo. Uno podría estar en desacuerdo con Juan porque hay un genuino conflicto de evidencias acerca de la tardanza de María. De esta manera, uno podría atribuirle desconocimiento a Juan aunque nos pongamos

\footnotetext{
${ }^{10}$ Se puede discutir si hay una continuidad entre el aspecto epistémico y el pragmático de las atribuciones de conocimiento, para esto véase: Loader (2012).

${ }^{11}$ Cfr., Kvanvig (2011).
} 
en su lugar, simplemente por interpretar distinto la información o evidencia disponible, especialmente cuando se centra en la posibilidad que tiende a sobrevalorar su probabilidad ${ }^{12}$.

Por supuesto, EE puede llegar a ocasionar un conflicto de argumentos en los que la evaluación de las atribuciones también sea falible. Por ejemplo, alguien podría pensar que Juan es epistémicamente inocente al atribuir falsamente conocimiento cuando en realidad no lo era o, a la inversa, pensar que es fue indolente en sus esfuerzos epistémicos cuando en realidad hizo todo lo habitualmente necesario para atribuir conocimiento. Errores de este tipo pueden ser considerados como una falla de apreciación importante. Por supuesto, uno podría juzgar la inocencia epistémica a partir de una atribución falsa de conocimiento - acerca de dicha inocencia - que a su vez pretende ser inocente. Sin embargo, en las ideas y vueltas del ejercicio dialéctico hay un aspecto pragmático que no debe ser olvidado: no solamente en el contexto de habla de quien atribuye conocimiento y que ha sido interpretado de alguna manera por los interlocutores, sino que también en aspectos relacionados con la acción y las preferencias que facilitan la inocencia epistémica de grupos de atribuciones. Los fallos anteriores, junto con los recursos pragmáticos en juego, dejan al descubierto que no hay una vía directa que conduzca de EE a IE.

La empatía con quien atribuye conocimiento depende de cierta relevancia pragmática. En la medida que uno es sensible al contexto del otro, puede ajustar las excusas epistémicas de acuerdo con sus propias creencias. Esta capacidad de ajuste permite motivar la búsqueda de información. Si las atribuciones epistémicas se sostienen mediante motivos y objetivos no epistémicos, entonces las normas epistémicas que describen el comportamiento apropiado de formación de la IE proporcionarán los medios para recopilar lo que a menudo se considera como evidencia.

La atribución de conocimiento de Juan puede apoyarse en excusas que pueden entenderse al menos de dos maneras: (i) en términos evidencialistas, como un plexo de proporciones con relativamente alta de probabilidad de constituir evidencias en un mismo contexto; (ii) en términos de fiabilidad, cuando se atiende a una alta proporción de resultados verdaderos por un proceso en un marco externista ${ }^{13}$. Cualquiera que sea el camino que uno decida tomar, si las intuiciones más elementales no se corresponden con la interpretación de las posibilidades que contrastan con las atribuciones, parecería que no hubiera un fundamento racional para el punto de partida de una excusa epistémica. Así, tanto EE como IE contrastan con cierto factualismo epistémico, que considera como constituyente a la posición ontológica de que hay hechos robustos que se destacan como hacedores de verdad para las atribuciones de conocimiento.

Como se ha argumentado, cuando alguien se encuentra en un contexto muy exigente es más cuidadoso en atribuir conocimiento apresuradamente. Esta exigencia vuelve más complicado encontrar excusas y consecuentemente ser epistémicamente inocente. También los contextos más exigentes son más dignos de debate. Quizás poco importe si la atribución de conocimiento de Juan acerca de los graneros sea verdadera; pero si de la atribución de Juan dependiera la vida de María, entonces sí importaría mucho su verdad. Los errores son frecuentes en atribuciones poco importantes, son menos frecuentes cuando se trata de atribuciones importantes. Esto es que si bien puede haber fallos, estos son menos frecuentes porque las atribuciones de conocimiento son menos frecuentes. Ahí dónde el error conlleva costos importantes, la atribución de conocimiento es menos frecuente que aquellos contextos donde el error tiene costos mínimos.

\footnotetext{
${ }^{12}$ Para un desarrollo de una idea similar, véase Conee \& Feldman (2004).

${ }^{13}$ Cfr., Goldman (1986)
} 
Finalmente, tanto EE como El, puede absorber las proposiciones del tipo "sé que $p$, pero podría ser que no- $p$ ", de modo que una atribución de conocimiento llevaría implícita la proposición "puede ser que no-p", implicando pragmáticamente que existe una probabilidad significativa de error ${ }^{14}$. Así, las condiciones de verdad de las atribuciones de conocimiento con sus respectivas excusas dependen, en parte, de la importancia práctica de $p$ para el sujeto, porque el significado práctico de $p$, como su valor teleológico, es parte de lo que determina si el sujeto atribuye el conocimiento de que $p$ es el caso. Allí dónde el riesgo de equivocarse se interpreta como alto, se abandona la posibilidad de atribuir de conocimiento. Pero, nuevamente, en contextos que implican un costo importante, se abandona dicha posibilidad de atribución, aun cuando el riesgo sea mucho más bajo. Esta aversión al riesgo significa que hay menos EE que sean aceptadas y que IE es más sencilla de conseguir en algunos contextos que en otros.

\section{Cuarto: cinco objeciones}

Llegados a este punto, se pueden presentar cuatro objeciones elementales. La primera ataca la idea de que la $\mathrm{EE}$, afirmando que puede implicar distintas forma retóricas que llevan convencer a los interlocutores de que cualquier atribución de conocimiento es plausible. La segunda de las objeciones es una continuidad de la primera y radica en considerar la intrusión pragmática como una puerta al relativismo que convierte a la epistemología, ante todo, en un fenómeno lingüístico. La tercera ataca directamente la concepción contrafáctica de la IE, argumentando que resulta imposible saber qué alternativas son procesadas adecuadamente por los sujetos y cuáles no. La cuarta objeción amplía la tercera, haciendo que IE parezca excesivamente vaga de manera tal que también afecte a EE.

\section{Primera objeción}

Se ha presentado la idea de que EE sirven especialmente para explicar las atribuciones falsas de conocimiento, ofreciendo una defensa razonable de porqué se produjo atribución. A su vez se ha argumentado que EE facilita no una atribución de conocimiento en especial, sino el grupo de atribuciones implicadas. De esta manera, se tropieza con dos inconvenientes. Por un lado, dos excusas contrarias pueden defender la misma atribución de conocimiento, haciendo que la decisión de elegir entre ellas sea una mera cuestión retórica, es decir de cómo los sujetos manejen ese grupo de excusas, y cuyo resultado es una flagrante irracionalidad epistémica. Por otro lado, y a la inversa, muchos grupos de atribuciones de conocimiento pueden ser defendidos por una misma excusa - incluso se podría pensar en una excusa que sirva para defender cualquier atribución -, con lo que no se podría diferenciar las excusas que son razonables de las que no lo son, pues solamente habría una. Dejándonos, nuevamente, a merced de una decisión en base al buen o mal manejo retórico.

\section{Segunda objeción}

Conectada a la anterior objeción se puede pensar que EE permiten defender cualquier tipo de atribución de conocimiento. Asimismo IE implica que no hay hechos que estén en sí mismos vinculados con la atribución de conocimiento, sino la IE es relativa a las excusas

\footnotetext{
${ }^{14}$ Análogamente como sostiene Hawthorne (2004) suena extremadamente extraño afirmar "sé que $p$ pero hay una posibilidad de que no- $p$ " o "Sé que $p$ pero hay una posibilidad de que $q$ (donde se sabe que $q$ es incompatible con $p$ )". Sin embargo, de seguir el camino falibilista esta extrañeza se disipa a través de consideraciones pragmáticas que hacen que las atribuciones de conocimiento estén sujetas a las normas de un contexto de evaluación de verbo "saber" cuya relación con la facticidad sea laxa.
} 
epistémicas aceptadas por un sujeto en una determinada comunidad. Dado que puede haber incompatibles excusas para una misma atribución y no hay un contraste directo con la facticidad, entonces la epistemología como disciplina tendrá sentido dentro de un fenómeno lingüístico lindante al relativismo.

\section{Tercera objeción}

Una tercera objeción es paralela a la segunda, pero es concebida desde un punto de vista más general. Se ha sugerido que $S$ puede hacer falsas atribuciones de conocimiento ignorando evidencia disponible y no es culpable cuando (a) no es consciente de su ignorancia, y (b) quienes lo juzgan, se ponen en su lugar y reconocen que no serían conscientes de tal ignorancia, pero tanto las condiciones (a) y (b) no alcanzan para establecer una distinción clara entre "responder razonablemente" y "tener una creencia razonable". Así, Juan responde razonablemente al hecho de que María no llega a la reunión, pero no tiene una creencia razonable respecto al conocimiento de María. De manera que su respuesta es inocente respecto a la evidencia disponible y que lo hace atribuir conocimiento, pues cumple la condición (a) y (b); pero es irresponsable respecto a la atribución de conocimiento en sí misma, pues no ser consciente de la propia ignorancia no es razón suficiente para mantener una creencia falsa debido a que existen falseadores (defeaters) normativos - dudas o creencias de las que el receptor debería haber dado ciertas evidencias, indicando que la proposición transmitida por el testimonio es falsa. Así, este principio sería una excusa para nuestra respuesta a nuestra evidencia disponible, y no para nuestra atribución de conocimiento, pues ella implica que tengo una creencia sobre alguien. Por ejemplo, Juan responde a una razón epistémica de forma adecuada, pero no eso no implica que la creencia formada por esa razón epistémica sea racional. Alguien lo engaña y le dice que las mascarillas contra el coronavirus no son efectivas, su respuesta razonable es abandonar su uso y buscar otras alternativas. Pero su creencia que las mascarillas no son efectivas no es razonable ${ }^{15}$.

\section{Cuarta objeción}

A lo largo del escrito se ha sugerido que las atribuciones de conocimiento conforman una relación tríadica entre el sujeto, el objeto y las atribuciones posibles que son desestimadas por contraste a la realizada. Estas atribuciones posibles podrían traer consigo un nuevo grupo de excusas epistémicas, de aquí que se produzca un espacio para la invasión pragmática y que haya discusión, incluso desacuerdo en torno a la inocencia epistémica. No obstante, la noción de posibilidad resulta muy vaga, y puede abarcar varios aspectos que van desde lo metafísico hasta lo deontológico. Aunque estos diferentes aspectos tengan en común que la base modal es un mecanismo de explicación semántica contextualmente determinada, no hay manera de describir cómo las posibilidades determinan la inocencia epistémica.

\section{Quinta objeción}

Según IE, la ignorancia ha de entenderse como ausencia de conocimiento, pero también puede pensarse como ausencia de creencia, siendo una de las condiciones del conocimiento, con lo cual puede aplicarse a múltiples casos: la proposición atribuida, las evidencias para la atribución, las posibilidades relevantes no consideradas, el riesgo de error y la importancia del contexto. En este sentido, IE parece bastante vaga y afecta a EE, pues parece muy complicado especificar por qué "ponerse en el lugar del otro" es un principio

\footnotetext{
${ }^{15}$ Agradezco a un árbitro anónimo de esta revista que por exponer claramente parte de esta objeción.
} 
generalizable de inocencia epistémica. Dicho de otra manera, si el requisito subyacente es que la situación de Juan no sea idiosincrásica, sino que sea generalizable, ¿no bastaría con exigir que quienes lo juzgan, explícita o implícitamente, reconozcan que en esa situación tampoco ellos serían conscientes de su propia ignorancia, dejando abierto el mecanismo de generalización -como ponerse en el lugar del otro o la reflexión acerca de la situación de Juan, u otros-? Si las condiciones de inocencia epistémica han de ser complementada con consideraciones pragmáticas, entonces se mezclarían con las condiciones ya existentes y sería complicado mostrar el lugar epistémico que ocupan.

\section{Respuesta a la primera objeción}

Para ilustrar una respuesta a la primera objeción, supóngase el caso de un físico medieval promedio, que sostiene que Ptolomeo sabía que la tierra era el centro del universo. ¿Es culpable de no saber que estaba en un error? ¿Debería ser consciente de su propia ignorancia? ¿Es capaz de emplear razones acerca de sus atribuciones de conocimiento? Por supuesto, no tienen ninguna obligación de reflexionar sobre los principios que subyacen al grupo de atribuciones de conocimiento que conforman la astronomía medieval, pues solo se reflexiona acerca de los principios fundamentales de una disciplina cuando se ponen en duda o cuando son severamente criticados, o cuando no es unánimemente reconocida su verdad. Pero no es el caso de nuestro físico medieval. Por lo tanto, uno podría decir que si alguien hubiera puesto en duda su conocimiento, él hubiera desplegado una serie de argumentos que demuestren su inocencia epistémica. Si nuestro físico medieval hubiera nacido en la época de Galileo, entonces debería reflexionar sobre los fundamentos de la física Ptolemaica. En este sentido, la ignorancia de que ignora no parece ser suficiente para demostrar su inocencia. Si pensamos que el físico medieval atribuía conocimiento de acuerdo con los estándares de la época, estos estándares pueden servirle de excusas a sus detractores. Así, la ignorancia epistémica del físico medieval es seriamente considerada si quienes los juzgamos, aún desde el punto de vista del siglo XXI, se ponen en el lugar de él y terminan persuadidos de que no podrían pensar de manera distinta. Se puede, entonces, encarar la primera objeción desde este punto de vista. Por un lado, que dos atribuciones de conocimiento contradictorias puedan basarse en un mismo grupo de excusas, no quiere decir que la aceptación de la atribución se encuentre librada a una habilidad retórica. Así, nuestro físico medieval puede apelar a las mismas excusas que uno contemporáneo, ambos sosteniendo tesis contradictorias, siempre y cuando las excusas sean los suficientemente generales. Más se ahonda en la generalidad de la excusa, quizás por medio de repreguntas, menos probabilidades hay para que las excusas sean las mismas. La decisión de si una excusa es mejor que otra, en este caso, se basará en los cánones epistemológicos imperantes en la época en las que se las evalúa. Que no haya una racionalidad olímpica, es decir la misma en todas las épocas y en todas las circunstancias -generalmente este tipo de racionalidad es eurocentrista -, no quiere decir que las decisiones en este tipo de casos sean irracionales. De esta manera puede haber una excusa muy general que abarque muchos grupos de atribución de conocimientos, aunque el exceso de generalidad suele ser sancionado con falta de credibilidad, pues suele aludir a cierta indolencia. Por otro lado, dos excusas contrarias pueden permitir una misma atribución de conocimiento. Muchas veces al conocimiento se llega por caminos distintos, al igual que los descubrimientos. Uno puede presentar argumentos distintos para explicar un mismo fenómeno, la vía matemática y la vía conceptual pueden proveer argumentos distintos para explicar un mismo fenómeno y con ello una misma atribución de conocimiento. Si se piensa en el físico medieval una excusa podría encajar con la mera observación y otra muy distinta con el testimonio de físicos que lo precedieron. De dos maneras 
distintas se obtiene la misma atribución de conocimiento. Sin embargo, importa aclarar los siguiente: que haya un intercambio dialéctico entre las excusas epistémicas, no quiere decir que la inocencia epistémica sea un mero problema retórico. Por supuesto, hay casos que pueden ser controversiales. Pero lo que importa para nuestro propósito no es presentar un abanico de situaciones en las que se puede discutir si uno es epistémicamente inocente o no. Lo que se pretende es indagar en cómo se aplica el principio de inocencia epistémica y cuáles son sus límites.

\section{Respuesta a la segunda objeción}

Como se ha dicho, esta segunda objeción se encuentra ligada a la primera. La idea de IE es normativa, como toda norma está sujeta a cambios, correcciones, rechazos y es objeto de debate. Incorporar un espacio pragmático para el debate de porqué, por ejemplo, Juan es inocente, no implica que en ese espacio valga cualquier excusa. Las normas son relativas a un contexto, o si se quiere ir más lejos, utilizando la expresión en sentido wittgensteniano, a una forma de vida. O dicho más específicamente, tanto una atribución de conocimiento como sus excusas explican algo cuando son compartidas, que pueda ser una práctica entendida por otros ${ }^{16}$.

De acuerdo con el contexto los estándares de evaluación de las atribuciones de conocimiento hacen que una excusa sea pertinente o no. Por lo tanto, IE no se adscribe en un relativismo absoluto, sino moderado. Este tipo relativismo respecto a las normas no implica un rechazo a las pretensiones de verdad de las atribuciones, ni pone en duda que el término "conocimiento" sea un fáctico, algo que por cierto ha sido muy discutido ${ }^{17}$. Dicho de otra manera, que uno sea inocente atribuyendo falsamente conocimiento implica que las pretensiones de verdad sí importan. Por último, que la epistemología como disciplina tenga una base lingüística no la hace dependiente del lenguaje. De hecho en este trabajo no se ha tratado con el conocimiento, sino con las atribuciones de conocimiento, esto marca una importante diferencia. Mientras que las atribuciones son enteramente un fenómeno lingüístico, el conocimiento entendido como un estado o proceso mental podrían diferenciarse del fenómeno lingüístico.

\section{Respuesta a la tercera objeción}

Como se ha dicho esta objeción es general y, por lo tanto, debe responderse también de forma general. Por su puesto, Juan puede racionalizar su respuesta de porqué creyó que María no llegaría tarde, a pesar de que su creencia podría no haber sido racional. Una diferencia elemental entre tener una creencia racional y los diversos procesos de racionalización de las creencias es que mediante a procesos de racionalización uno puede inventar casi cualquier pretexto respecto sus propias equivocaciones, mientras que las creencias racionales no implican categorías pragmáticas del orden de los pretextos o las excusas. El problema está que tanto los procesos de racionalización como las creencias racionales cumplen la función de que Juan pueda responder razonablemente. Por este motivo, IE tiene un valor pragmático y no meramente semántico para poder identificar, de acuerdo con el contexto, aquello que se considera un mero pretexto de aquello que no y así dirimir responsabilidades. Siguiendo el ejemplo de la objeción, si alguien engañara a Juan y le dice que las mascarillas contra el coronavirus no son efectivas, su

\footnotetext{
${ }^{16}$ En este punto se podría utilizar una estrategia davidsoniana donde el rol justificatorio de una razón depende de su rol explicativo y el rol explicativo debe fundarse en una práctica compartida, véase: Davidson (1980). Para el desarrollo de esta estrategia, cfr., Pedace (2017).

17 Para ver una discusión en torno a la facticidad del término "conocimiento", véase Hazlett (2010).
} 
respuesta razonable es abandonar su uso y buscar otras alternativas. Pero su creencia que las mascarillas no son efectivas no es razonable, siempre en el sentido de que no posee ninguna evidencia relevante que la justifique (de hecho, las fake news funcionan de esta manera); ¡evidencia que Juan debería buscar dada la importancia del tema! En cambio, en asuntos de poca importancia la búsqueda de evidencias más allá del mero testimonio puede llegar a ser una pérdida de tiempo. En este caso, la inocencia epistémica es mucho más frecuente.

Ahora bien, la presente objeción también tiene otra cara, que se refiere a cómo se comportan articulación de falseadores (defeaters) normativos con situaciones de atribución de conocimiento irresponsable. Para abordar esta cuestión conviene aclarar que, por un lado, en el contexto del presente escrito, un falseador sería un tipo de aserción que bloquea o silencia la fuerza normativa de ciertas pretensiones de conocimiento en la deliberación racional. Así, la capacidad de defensa de los falseadores normativos se refiere más un problema, que una solución: Juan le atribuye conocimiento a María, y mostrar que tal atribución es normativamente inadecuada desvía la atención desde la atribución del enunciado hacia la atribución a la norma, estableciendo un nuevo problema. Por otro lado, se puede recurrir a la idea de que de la misma manera que existen falseadores, también puede haber falseadores falseados producto de la misma deliberación, complejizando aún más el problema: Juan podría mostrar evidencias convincentes de que los falseadores son inadecuados o no determinantes para su atribución de conocimiento. Las aclaraciones que haga Juan respecto a la falsación normativa también se pueden coordinar con IE. De modo que la falsación planteada puede ser recibida por los interlocutores incluso como un problema legítimo, pero que cualquiera en el lugar de Juan podría no haber identificado. De la misma manera, Juan puede darle prioridad a algunas creencias por sobre otras que podrían falsearla o viceversa, y quien se ponga en el lugar de Juan asignar las mismas prioridades juzgando que Juan es epistémicamente inocente ${ }^{18}$. Nuevamente, si alguien cuestiona que Juan responde a una razón de forma adecuada, pero sin que su creencia formada por esa razón epistémica sea racional (ex ante), entonces ese alguien debería dar una razón de por qué tal respuesta no estaría formada racionalmente, a la vez que Juan también podría ensayar su defensa (ex post), sin que esto perjudique su inocencia epistémica.

\section{Respuesta a la cuarta objeción}

La cuarta objeción tiene dos partes. La primera se centra en el aspecto modal de IE como de EE. En cambio, la segunda se centra en las cataratas de excusas que pueden surgir de un desacuerdo en la inocencia de quien atribuye.

En la primera parte de esta objeción hay una especie de desplazamiento, que va desde la inocencia epistémica hacia la capacidad que tienen los sujetos de decidir cómo actuar. Este desplazamiento es importante porque lo que se juzga cuando se habla de inocencia epistémica es, en definitiva, la veracidad de nuestras atribuciones. Juan puede responder, "sé que estaba atribuyendo falsamente conocimiento, pero no puedo evitarlo"19. De aquí la necesidad del aspecto modal de las atribuciones de conocimiento. Si Juan no puede evitar atribuir de la manera que lo hace, esto lo vuelve epistémicamente inocente. Con lo cual el principio de IE todavía se mantendría. Para aclarar un poco este punto se puede recurrir al fenómeno de que hay creencias que no se puede evitar tener a pesar de que todas las evidencias apunten en

\footnotetext{
${ }^{18}$ El desarrollo de una discusión acerca de la relevancia de los falseadores normativos conduce al debate sobre cómo están organizados lógicamente. Sin embargo, tal desarrollo pertenece a una explicación formal la teoría normativa de las razones, que está fuera del alcance de este trabajo.

${ }^{19}$ Esto contrastaría con la máxima de cualidad de Grice (1975): "no digas lo que crees que es falso, o para lo cual careces de evidencia adecuada".
} 
sentido contrario ${ }^{20}$. Desde este punto de vista no se analiza si el sujeto está en posición de saber lo suficiente para atribuir conocimiento, sino que se juzga solamente los hechos que conforman la atribución. Si Juan no puede hacer otra cosa, si su conducta está completamente determinada, entonces no habrá espacio para su culpabilidad. Por ejemplo, Juan sabe que es muy poco probable que María se haya accidentado en el camino, sin embargo también él tiene terror a las carreteras y no puede dejar de creer que María se accidentó. Asimismo, si Juan sabía que estaba cometiendo un error y quería evitarlo pero no pudo, entonces tampoco es culpable desde el punto de vista de los hechos, ni tampoco es culpable epistémicamente. Pero ¡Juan no es consciente de su propia ignorancia! Sabe que no debe creer aquello que creer y lo cree igual. Sin embargo, si reemplazáramos "creencia" por "saber", entonces se llega a una idea absurda: Juan sabe que no debe saber aquello que sabe pero lo sabe igual. No hay ningún caso que se amolde a la anterior circunstancia. La influencia de la epistemología de la creencia sobre la noción misma de conocimiento conduce a este tipo de malos entendidos. ¿Es distinto con las atribuciones de conocimiento? Reemplacemos entonces "creencias" por "atribuciones de conocimiento": Juan sabe que no debe atribuir conocimiento acerca de aquello que atribuye, pero atribuye conocimiento igual. En el caso de la atribución de conocimiento, la idea parece funcionar mejor, y esto puede pensarse como a la diferencia entre "saber" y "atribuir conocimiento" 21 . De esta manera el aspecto modal de las atribuciones de conocimiento juega un papel importante para poder decidir si una excusa sería pertinente o no en el caso que se diera.

Respecto a la segunda parte de la objeción, se puede considerar la presencia de sesgos focales, en el que ciertas alternativas no se procesan adecuadamente. Y, siguiendo la línea de la anterior argumentación, uno estaría tentado en aceptar excusas en contra de la evidencia disponible o rechazar excusas aunque haya evidencias de lo contrario. En este sentido, el panorama dialéctico llegaría a ser muy complejo. Por ejemplo, una excusa puede ser aceptada por algunos pero no por otros, alguno pueden aceptarlas procesando inadecuadamente la evidencia, mientras que otros adecuadamente. Aunque ni EE ni El dicen nada acerca del desacuerdo acerca de la culpabilidad o inocencia epistémica, sí sugieren que hay un ámbito compartido en el que pueden ser calificadas normativamente. El problema en todo caso estriba en que no existe recomendación alguna acerca del correcto procesamiento de la evidencia, porque no existe un correcto procesamiento de la evidencia para todas y cada una de las atribuciones de conocimiento. De esta manera, no solo tratan a las atribuciones de conocimiento como si fueran un fenómeno lingüístico, sino que también importa lo que el fenómeno lingüístico representa. En situaciones donde la legitimidad de una atribución de conocimiento resulta vaga, el ejercicio retórico puede formar parte de las excusas pero esto no es lo mismo que decir que, gracias a ello, uno siempre sea considerado epistémicamente inocente. Demasiado escepticismo sobre este tipo de intuiciones puede ser contraproducente de cualquier esfuerzo epistémico y conducir al escepticismo global.

\section{Respuesta a la quinta objeción}

La cuarta objeción desarrolla la idea de vaguedad de la objeción anterior, que solo se enfocaba en el aspecto modal. Esta última estrategia sugiere que sostener que es por lo menos extraño tener derecho a equivocarse cuando se intenta exculpar a quien atribuye falsamente

\footnotetext{
${ }^{20} \mathrm{Sin}$ embargo, es posible pensar en casos que uno sabe lo que hace $y$, no obstante, no puede dejar de hacerlo. Pensamos en el caso extremo de que Juan tiene una predisposición innata a atribuir conocimiento falsamente, y aun sabiendo que su atribución es falsa no puede evitarla. En este tipo de casos no se cumpliría el principio de IE, pero tampoco podríamos sostener que Juan es culpable o que no es inocente. Así, IE seguirá funcionando en casos donde las atribuciones de los agentes no están inevitablemente determinadas.

${ }^{21}$ Para esta diferencia, que excede el marco del presente trabajo, véase: Blome-Tillmann (2013).
} 
conocimiento. La extrañeza se origina porque resulta complicado comprender el rol pragmático de nuestras atribuciones de conocimiento. Sin embargo, la pragmática no es una condición más como la evidencia o las posibilidades contempladas, sino que es lo que permite que tales condiciones se cumplan, no es un pieza más del rompecabezas sino el modo en que las piezas van unidas. Hay una importante diferencia en esto, porque, aunque "ponerse en el lugar del otro" sea un principio generalizable para IE, esto no presupone que se generalice de cualquier modo. Por ejemplo, Juan puede ser inocente de atribuir conocimiento porque si sus interlocutores se ponen en su lugar, hubieran atribuido conocimiento de la misma manera. Pero Juan también puede ser inocente porque las excusas que da son los suficientemente convincentes sin que nadie llegue a indagar sobre ellas y si uno se pone en el lugar de los interlocutores, procediendo análogamente, también declararía inocente a Juan. La relación pragmática entre las excusas y la inocencia es diferente en ambos casos. En este sentido, Juan tiene derecho a equivocarse y cuando presenta las pertinentes excusas lo que está haciendo es manifestando ese derecho. Es decir, mediante las excusas Juan exterioriza o proclama dicho derecho.

Se podría objetar que aunque la excusa epistémica exculpe al sujeto, con lo que este es declarado inocente; no implica que tenga derecho a equivocarse. Así, si uno tiene derecho a permanecer callado -como en un interrogatorio judicial-, puede ejercitarlo si quiere; pero según IE uno no puede ejercitar su "derecho" a equivocarse si quiere. Esto conduce a la confusión entre el derecho a exculparse (defenderse de los errores) y el "derecho" a equivocarse. En estrategias como estas, importa subrayar que si bien la culpa puede ser compartida, la inocencia no y que hay un sentido de "inocencia" que no es juzgado y otro que sí. Esta diferencia es intuitiva, la inocencia no juzgada de una atribución falsa de conocimiento -relacionándolo con el punto principal de la cuarta objeción- puede implicar la indolencia de quienes deberían juzgarla o, simplemente, porque la atribución es tan irrelevante que no merece la pena el juicio, en casos como estos nadie se pone en el lugar del otro. En cambio, la inocencia juzgada requiere de un compromiso con la evaluación de la atribución. Este puede expresarse en enunciados del tipo: "no lo sabía, pero no tenía por qué saberlo" o "deberías haberlo sabido" o"no habría manera de que lo hubiera sabida".

Finalmente, en el rol pragmático de las atribuciones, condiciones como por ejemplo la recolección de evidencias o las dependen del contexto de evaluación y es por eso que IE podría parecer, en un principio, bastante vaga. La idea central en este punto es que la responsabilidad epistémica está emparentada, por un lado, con la intuición de que atribuir conocimiento de que $p$ es no atribuir conocimiento de todas las variables que implican no- $p$ y, por otro lado, con la imagen de que hay aspectos no epistémicos de las atribuciones de conocimiento que poseen un rol importante en la inocencia epistémica.

\section{Conclusiones}

Se ha sostenido que la inocencia epistémica se encuentra basada en las excusas razonables que justificarían las atribuciones de conocimiento. Este planteo conduce a que si $S$ es inocente epistémicamente es porque no es consciente de que ignora evidencias relevantes, a la vez que quienes legitiman su inocencia, de ponerse en el lugar de $S$, también habrían atribuido conocimiento de la misma manera. En este sentido, las excusas epistémicas coordinan una batería de razones con las atribuciones de conocimiento.

Por un lado, un aspecto importante las excusas epistémicas es que funcionan como explicaciones causales. Cuando Juan dice que la tardanza de María se pudo producir debido a un accidente de camino a la fiesta, es porque considera que su atribución de conocimiento 
responde a una parte particularmente importante o destacada de la historia causal detrás de lo que percibe que está ocurriendo. Así, Juan puede atribuir falsamente conocimiento solo al suponer que hay evidencias suficientes en la historia que cuenta, y que funcionaría como excusa, siendo realmente que estas evidencias sirvieran como causa principal de que María se haya demorado. Asimismo, las excusas epistémicas, en tanto explicaciones razonables, sirven para contestar a preguntas que ponen en duda la atribución de conocimiento o desafiar implícitamente su autoridad. A preguntas de estilo de “¿cómo sabes que $p$ ?" uno puede responder con una historia causal que omita las condiciones externas de quienes atribuyen.

Por otro lado, tanto la IE como las EE funcionan en un determinado contexto. En contextos epistémicamente exigentes -cuando hay mucho en juego- se intentará de evaluar más profundamente la información disponible, y las atribuciones de conocimiento serán también más difíciles de realizar, pues será complicado elaborar historias causales que sean aceptadas. Además, en estos contextos, existe la dificultad extra de ponerse en el lugar del otro, simplemente porque puede llegar a ser un lugar extraño para quienes no sean expertos en el tema.

Por último, que uno tenga derecho a equivocarse no significa que siempre pueda ser inocente al realizar atribuciones falsas de conocimiento. La labor de la pragmática referente a nuestras evaluaciones diarias de las acciones, a los razonamientos y a los compromisos doxásticos de los demás, invaden nuestras atribuciones de conocimiento y son necesarias para el pasaje desde la EE hacia IE. Y es, justamente, dicha diversidad pragmática la que abre la puerta a que las atribuciones falsas de conocimiento sean sospechosas en todo contexto, además de candidatas a ser usadas por el escepticismo epistemológico.

\section{Referencias}

BLOME-TILLMANN, M. Knowledge and implicatures. Synthese, 190(18), p. 4293-4319, 2013.

BONJOUR, L. The myth of knowledge. Philosophical Perspectives, 24(1), p. 57-83, 2010.

CONEE, E.; FELDMAN, R. Evidentialism: Essays in Epistemology. Oxford: Clarendon Press, 2004.

DAVIDSON, D. Essays on Actions and Events. Oxford: Clarendon Press, 1980.

FELDMAN, R. Fallibilism and Knowing That One Knows. The Philosophical Review, 90, p. 266-82, 1981.

GOLDMAN, A. Discrimination and perceptual knowledge. Journal of Philosophy, 73, p. 771-791, 1976.

GOLDMAN, A. Epistemology and Cognition. Cambridge: Harvard University Press, 1986.

GRICE, P. Logic and Conversation. In: MORGAN, E.B. Syntax and Semantics, Vol. 3, Speech Acts, p. 41-58. New York: Acedemic Press, 1975.

HAWTHORNE, J. Knowledge and Lotteries. Oxford: Clarendon Press, 2004.

HAZLETT; ALLAN. The myth of factive verbs. Philosophy and Phenomenological Research, 80(3), p. 497-522, 2010.

HEATHWOOD, C. Moral and Epistemic Open Question Arguments. Philosophical Books, 50, p. 83-98, 2009.

HETHERINGTON, S. Concessive knowledge-attributions: fallibilism and gradualism. Synthese, 190(14), p. 2835-2851, 2013.

KVANVIG, J. Against Pragmatic Encroachment. Logos \& Episteme, 2(1), p. 77-85, 2011.

LEWIS, D. Elusive Knowledge. Australasian Journal of Philosophy, 74(4), p. 549-567, 1996. 
LOADER, P.The epistemic/pragmatic dichotomy. Philosophical Explorations, 15(2), p. 219-232, 2012. PEDACE, K. Mente y Lenguaje. Buenos Aires: SADAF, 2017.

SCHAFFER, J. From Contextualism to Contrastivism. Philosophical Studies, 119(1), p. 73-104, 2004.

SCHAFFER, J. Contrastive Knowledge Surveyed. Nous, 46(4), p. 675-708, 2012.

STANLEY, J. Knowledge And Practical Interests. Oxford: Oxford University Press, 2005.

SULLIVAN-BISSETT, E. Implicit bias, confabulation, and epistemic innocence. Consciousness and Cognition, 33, p. 548-560, 2015.

VAVOVA, K. Irrelevant influences. Philosophy and Phenomenological Research, 96(1), p. 134$152,2018$.

\section{Sobre o autor}

Rodrigo Laera

Doutor em Filosofia. Pesquisador Conicet/Sadaf (Argentina). E-mail: rodrigolaera@gmail.com

Recebido em: 06/02/2020.

Aprovado em: 03/04/2020. 